\title{
Learning Never Ends- Lifelong Learning And A Career In Life - Reports From Research 2014-2018 Gdynia/Poland
}

\author{
Kamila Olga Stępień-Rejszel
}

Uniwersytet Gdański

\begin{abstract}
A great deal has already been said about the importance of lifelong learning. The number of European documents that raise discussion about the essence of L.L.L. is indeed large. It is enough to mention here, for example, the UNESCO Report "Learning to be" initiated in 1971, the Club of Rome Report "Learning without borders" or the Jacques Delors Report published in 1996, under the metaphorical title "Education, there is a hidden treasure in it". On the other hand, it is worth asking a question How do define lifelong learning of a person who had already undergone the standard education process in the 1980s and today are adults and function in the modern world, where learning has become a peculiar norm-key to the present day? The aim of the presentation is to present a picture of Life Long Learnig seen from the perspective of 40 year old residents of Gdynia and is the result of research on the $\mathrm{PhD}$ thesis entitled "Comprehensive learning variations in the light of the analysis of life careers of 40 year old residents of Gdynia. Biographical study.
\end{abstract}

Keywords: life careers, Life Long Learning, Gdynia, Poland, Biographical study. 